\title{
12
}

\section{ENERGY HUMANITIES AND THE PETROLEUMSCAPE}

\author{
Imre Szeman and Caleb Wellum
}

Recent debates around fossil fuels in Canada have brought home the importance of energy resources to the life of the country. They have also shown the importance of space to disputes over how, why, and whether fossil fuels should be used. The contentious function of oil in linking space and governance has been made clear in the extended struggle over the construction of pipelines from northeastern Alberta (close to the extraction site of the Athabasca tar sands) to the coasts, especially to the West Coast. For the Alberta provincial government and the Canadian federal government, pipelines have the potential to expand markets for Canadian oil, most of which goes to the US ${ }^{1}$; for the provincial government of British Columbia, through whose territory they must pass, and for many First Nations in the region, the structures pose more threat than opportunity. Some of the disputes over energy in Canada are based on environmental principles and the argument that oil must be left in the ground. In the case of the pipelines and in the case of recent challenges by conservative governments in Saskatchewan and Ontario to the federal carbon tax, the struggle is over politics rather than principles, and it often plays out in the construction and representation of space. Conservative governments want the business of fossil fuels to continue unabated, even as British Columbia's current left-of-center government seems intent on mitigating the outcomes of fossil fuel use, including the fires that have plagued its forests over the past several years.

Despite the fact that Canada's history and the space of its political sovereignty have been shaped in relation to resource extraction, it is safe to say that such practices have only recently animated vigorous public debate about their short- and long-term viability as well as their environmental implications. Yet these debates have only scratched the surface of the social and cultural commitments Canadians have made to their resource culture. This isn't to say that there aren't politically committed environmentalists in Canada, such as author Naomi Klein, whose contributions include her involvement in the 2015 Leap Manifesto, a document that demands restructuring Canada's economy to end fossil fuel use. Instead, it is to say, even as environmentalists push Canada to change its sources of energy, there has been less of a demand for an accompanying social transition. All too often, ending the use of 
fossil fuels is imagined as leaving almost everything the same, except for the source of energy that powers the country. It is assumed that current modes of work, economic organization, and daily life would continue unchanged. This limit of imagination doesn't plague Canada alone. We have all barely begun to discuss the profound changes to the existing petroleumscape that must accompany any transformation in global fossil fuel use.

For the interdisciplinary field of study known as the "energy humanities," there is a deep link between the energy on which society depends and the character of its cultural, social, political, and spatial forms. To put it directly, far from being just a neutral input into our society, energy plays an essential role in shaping who we are and how and where we live. The history and shape of modernity is deeply connected to the character of the energy that has been dominant over the past 150 years - fossil fuels — and the petroleumscape it has created. Since the mid-nineteenth century, changes in the forms of energy that we employ have altered what we are capable of, how we imagine ourselves, and the spaces we inhabit. The structure of transportation systems, the overall shape and design of cities, and the expansion of global trade are linked to the ease of access and affordability of fossil fuels, which has created durable structures such as refineries and highways that will have to be repurposed in a post-oil future. Much of the psychological, affective, and political characteristics of modernity-individuality, autonomy, self-development, and freedom, for example-are also connected to the ever-expanding use of fossil fuel energy and the spaces it has produced (Figure 12.1). This is especially the case since World War II, a period that has been described as the "Great Acceleration" by some scholars and as the "Great Derangement" by others. ${ }^{2}$

We are not claiming that there is a one-way cause-and-effect relationship between the expanded per capita energy use enabled by fossil fuels and the socio-spatial developments that characterize modernity. The relationship is dialectical: the advent of cheap and accessible

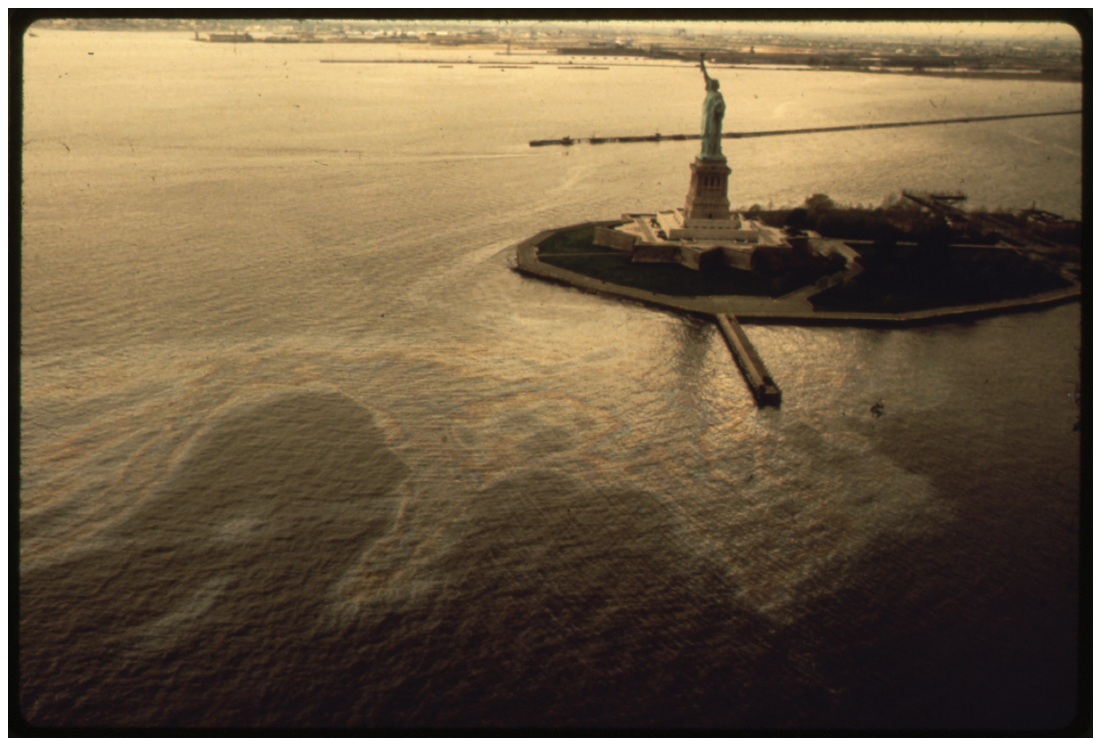

FIGURE 12.1 "Oil Slick Surrounds the Statue of Liberty in New York Harbor." Source: EPADocumerica-Chester Higgins. Record Group 412, National Archives II, College Park, MD. 
sources of energy helped to generate new forms of technology, infrastructure, and social behavior, which in turn lead to an ever-greater use of fossil fuels in a process Jeff Diamanti and Mark Simpson have termed "energy deepening." As Jean-Claude Debeir, Jean-Paul Deléage, and Daniel Hémery argue in their iconic history of energy:

while there is no energy determinism there is a powerful energy determination at work in all societies ... the energy determination is itself determined: it is the result of the interplay of economic, demographic, psychological, intellectual, social and political parameters operating in the various human societies. ${ }^{4}$

The process of a century and a half of energy deepening with fossil fuels, a continuous doubling down of social bets on this substance, makes it very difficult to imagine a quick, easy turning-off of the taps. If it were somehow possible to switch immediately from fossil fuels to (say) solar energy, much of global society would nevertheless remain a fossil fuel society, thanks in large part to the inertia of the global petroleumscape. Car-dependent suburbs cannot be quickly retrofitted for walkable density, nor can oil refineries easily be converted to other uses. Debeir, Deléage, and Hémery remind us that a true transition would require "a radical change in the key economic choices which shape civilization over long periods. What is required is a decisive broadening of political and social democracy, a profound change in individual behavior and educational systems. " 5 In other words, energy transition requires something akin to a political revolution, a new articulation of the commons to undergird and support the introduction of solar panels, electric transport, and sustainable configurations of space.

The intervention of the energy humanities is (i) analytic and conceptual, and (ii) speculative and political. With respect to the first, the fundamental goal of the energy humanities is to argue for the need to include energy in accounts that the human sciences offer of any subject whatsoever, with an emphasis on the history of modernity- the period during which rapid increases in energy use transformed human life experience. Accounts that foreground energy have already begun to re-narrate our understanding of key moments in the development of contemporary culture, society, and politics, as well as the spaces that shape them. The work of political theorist Timothy Mitchell stands out as one of the most powerful examples of this approach. In Carbon Democracy: Political Power in the Age of Oil, Mitchell connects (among other things) the shift from coal to oil as having a major impact on unions. As forms of energy moved by pipeline became dominant over coal, the capacity of unions to shut down energy flows from coal mines declined. The bigger takeaway from Mitchell's influential book is the link between the growing reliance on oil for energy and the emergence of what might be described as "democratic governmentality," that is, a form of governance that divides the commons to limit "claims for greater equality and justice." 6 This governmentality consigns particular concerns to distinct spheres, such as to nature or the private sphere, that are subject to specific rules that limit certain kinds of political claims. One of the most significant of these concerns is the topic of this volume: the claim over and right to construct the petroleumscape, and to do so largely in relation to the imperatives of government and business. Understanding energy in relation to the construction of space is essential to grappling with its political and socioeconomic force. While space is not always foregrounded in the wide range of inquiries collected under the umbrella term of "energy humanities," our description here of key moments in the constitution of this field should be seen as in the dialog with the spaces of petroculture. 
Like Mitchell, the work of Swedish historian Andreas Malm provides a reimagining of another key moment in the history of the present. The Industrial Revolution is often seen as a period in which liberal political ideology and technological advances improved the lot of humanity, a development signaled in the switch from water mills to more efficient and powerful factories and engines run on coal to ones fueled by petroleum, a foundational development in the history of the global petroleumscape. In Fossil Capital: The Rise of Steam Power and the Roots of Global Warming, Malm argues that the transition from water to steam was actually a form of class warfare. ${ }^{7}$ Coal was not cheaper than water, but it was more mobile, allowing factories to concentrate in cities in order to exploit unspecialized workers for the benefit of the factory owners. Other analyses have produced similar insights into the character of the present, including Amitav Ghosh's account of the inability of the modern novel to address climate change and Dipesh Chakrabarty's reframing of the terms on which historical research is carried out in light of global warming. ${ }^{8}$

The speculative and political dimensions of the energy humanities are an equally important element of the work it carries out. The absence of energy from our accounts of modernity has impoverished our understanding of it and limited our sense of the forces and imaginaries shaping the present, including the role of the petroleumscape in shaping perception. It has also made it difficult to respond effectively to one of the consequences of intense fossil fuel use: the production of ever-increasing levels of carbon dioxide that have induced global warming. The analytic work of the energy humanities produces an expanded sense of the social and infrastructural commitments that have been made to fossil fuels-commitments that constitute the "energy deepening" or "energy determination," so aptly captured in the petroleumscape concept. But when it comes to energy use, it is not enough simply to generate knowledge or insight into processes or protocols. It is vital to develop political responses at the right scale and at optimal sites, in order to begin to unravel the tightly coiled temporality of energy deepening.

Building on existing discussions in the energy humanities, ${ }^{9}$ we want to point to some ways in which including energy in our investigations generates insights into where we have been and where we might be going. Just how does the approach of the energy humanities generate new insights into the historical practices, processes, and spaces of the modern? And how, too, does it give us tools for revamping the work of what has come to be known as theory?

\section{Energy, History, Modernity}

The history of energy is often practiced as a form of economic or environmental history or as a historical subfield. Energy historians tend to examine the exploitation of different energy forms and technologies, highlighting their role in production and consumption more broadly as well as their social and environmental consequences. J. R. McNeill's environmental history of the twentieth century, Something New Under the Sun, Vaclav Smil's substantial scholarly corpus on the history of energy technologies and use, and E. A. Wrigley's work on the energy dynamics of the Industrial Revolution are key works in this vein. ${ }^{10}$ Each generated debate about the economic, political, and environmental consequences inherent in the history of energy and demonstrated that energy is an important factor in historical change. The historical claim of the energy humanities, however, is deeper and more radical: energy is a fundamental category of historical analysis to be added to the triumvirate 
of class, race, and gender. Like those categories, paying closer attention to energy in our histories will transform how we understand our societies and the spaces they inhabit. If the claim that there is a deep link between energy and the social and political is to stand and to be analytically useful, then the work of historicizing cultural imaginaries, social practices, and political formations in relation to energy must be at the core of historical praxis.

This approach is particularly apt for the history of modernity, which hinges on radically altered human capacities and imaginaries. Its purview includes revolutionary scientific and technological shifts (mobility, health, and communication); the emergence of nation-states and new political ideologies (democracy, communism, fascism); unprecedented population growth; mass production and consumption; mass migration; secularization; and the spread of new norms and values. The fact that these changes are unevenly distributed in space and time does little to detract from their historical and environmental importance. It only complicates potential responses to the challenge of climate change and imparts greater urgency to the creation of new narratives of modernity. We must now ask: To what extent is the history and status of modernity tied up with fossil fuels as well as the tendencies and imperatives that their use entails? How might new histories deepen our understanding of the commitments to fossil fuels that we have made? We will focus on the era of fossil fuels from the late eighteenth century to the present to suggest some ways that an analytical concern with energy opens up new understandings of the contingency and materiality of modernity and some of its fundamental categories, concepts, and spaces, that is, the complex web of distinct elements that constitute the petroleumscape.

Attention to energy, in the first place, can open up the histories of historical consciousness and crisis. This point begins with the basic insight that different forms of energy generate unique time and space relations. Chopping and burning wood for heat tends toward different temporalities than flicking on a natural gas furnace or stove. Drawing on bodily energies to walk and burning gasoline to drive similarly entail different experiences and expectations of time and space. Such distinctions may seem banal, but they suggest energy's role in deeper shifts in social and cultural awareness. The emergence of modernity revolved in large part around such reconfigured human relations to time and space and overlapped significantly with the eighteenth- and nineteenth-century energy transition from flows of solar energy (primarily expended via bodies) to the stock energies that powered machines and fueled-and continue to fuel-aspirations for a workless utopia.

According to the German historiographer Reinhart Koselleck, by the end of the eighteenth century modernity contained a "peculiar form of acceleration" generative of expanded historical consciousness - a sense that the future (the "horizon of expectations") could and should differ from the past (the "space of experience"). ${ }^{11}$ In this accelerating divergence of future from past lay the origin of "crisis," a transcendental placeholder that imparted meaning to history and demanded a new future. ${ }^{12}$ By the twentieth century, the ideology of "progress" was firmly entrenched, while thinkers like Walter Benjamin critiqued the culture of modernity in terms of speed and shock. ${ }^{13}$ Crisis (in this volume, see also Introduction, Strupp and Fuccaro) - a concept at the heart of the experience of modernity and of modernist critique-proliferated alongside and within the pervasive sense of acceleration most often symbolized by industrial machinery, trains, and automobiles that were, in turn, a condition of possibility to the world wars that scored the first half of the century. These fossil-fueled technologies then continued to generate further ruptures in the experience of time, remaking space along the way to accommodate their expansion. ${ }^{14}$ 
The energy humanities claims that this modernity of acceleration, abstraction, and crisis must be understood as a "petromodernity" - that is, as fueled by and coextensive with the mass consumption of fossil fuels that the global petroleumscape both embodies and abets. Its roots are therefore significantly material and historically contingent. This claim opens up all kinds of questions about the relationship between energy, experience, and capitalism. It encourages us to reexamine alternative orientations to time and struggles over time, such as those studied by E. P. Thompson and Anson Rabinbach in the context of the labor history of Western Europe in the seventeenth to the nineteenth centuries, to understand how the exploitation of fossil energies has remade time and space. ${ }^{15}$ It also demands that we historicize more recent structures of time and space. For instance, Malm has argued that the prerogatives of steam power within capitalism contributed mightily to the abstract reconfiguration of time and space to maximize productivity, separating human labor, bodies, and minds from natural spaces and temporalities. ${ }^{16}$ Cultural theorists Jonathan Crary and Dominic Pettman suggest that this process of abstraction and fragmentation has only intensified as capital turns from mining the resources of the earth to human attention and creativity as new sources of energy and profit. ${ }^{17}$ All these developments require enormous inputs of fossil fuel energy and carry social, economic, and political consequences that will reverberate well into the future. The key task-and analytical opportunity-of foregrounding energy in our accounts of modernity is to see how time and space are shaped by it, and to trace the multiple and intersecting consequences of that shaping.

Attention to energy also has the potential to illuminate the primary political forms of modernity: nationalism and the nation and their spatial dimensions. The history of nationalism parallels the mass availability of energy, flourishing in the nineteenth and early twentieth centuries alongside the fossil-fueled Industrial Revolution. Although its histories are complex and multi-causal, nationalism presupposes awareness beyond the local and a sense of a shared, national public sphere. Such cultural and psychological shifts, in turn, require mass mobility and communication technology to sustain the sense of a shared space of nationhood. Nationalism then presupposes large energy inputs to power communication and mobility, which in turn rely on infrastructures that knit spaces together and shrink the expanse of time, helping disparate communities and regions understand themselves as parts of larger wholes. Indeed, energy infrastructures, from hydroelectric dams and oil refineries to railways and highways, are often loaded with nationalist discourses of modernity, progress, and common purpose (in this volume, see Ramos, Uyttenhove, Peyerl, Couling, Scotto, Hindelang, and Hou). Fossil-fueled transportation technologies and manufacturing techniques also enabled mass mobilization at the scale of the nation to engage in nationalist conflicts, as both of the twentieth century's world wars attest. ${ }^{18}$ These ideas are speculative, but point to the possibility of formulating a theory of the nation that would reframe its history in terms of access to energy.

It is also useful to frame post-national one-worldist and "think global" politics, prevalent in globalization, multicultural, and climate change discourse, as deeply embedded in the energy abundance of the twenty-first century. These ideologies, which seek to supersede the nation in the interests of equality, peace, and a sustainable global future, emerged in response to the global conflagrations of the twentieth century, but they have also been enabled by energy-intensive infrastructures of global trade, mobility, and communications. What will be their future in a post-oil world? How might seeing the capacities and politics of energy resources at the heart of both nationalist and post-national imaginaries change our understanding of them? 
The historicizing claim of the energy humanities extends from modernity's configurations of time and space to concepts often taken to be fixed and scientific. Of these, perhaps the most important and under-analyzed is the concept of energy, which is typically defined as power or the ability to do work. The concept of energy is of course much more historically situated and complex than that, imbued with different social and political meanings embedded in time and place. Nearly thirty years ago, Rabinbach linked nineteenth-century notions of energy within physics and thermodynamics to the management and politics of labor through his analysis of the human motor metaphor. ${ }^{19}$ Since that time, little work has been done to historicize energy in the twentieth century, despite the rapid acceleration of energy production, consumption, and crisis that marked the era of mass automobility, nuclear power, and digital technologies. Since these changes have pervasively intensified our control over and reliance on non-bodily energies, we must reflect on the ways in which they may have reshaped the notions of energy that we presently rely on to understand the past and to imagine a world after oil.

One place to start is with the science of ecology, which developed its core concepts of the ecosystem and energy flow within the systems science research of the mid-twentiethcentury nuclear-industrial complex in the US as well as in response to the environmental catastrophes visited upon the world by automobiles and nuclear testing. The work of US ecologists Eugene and Howard T. Odum and their colleagues is particularly important for understanding how the nineteenth-century conception of energy as a universal force flowing through the laboring body was abstracted to fit the era of systems science and control. ${ }^{20}$ Working on sites of nuclear testing and power generation with support from the Atomic Energy Commission, systems ecologists developed a cybernetic idea of energy as flow through systems. This new notion of energy was as effectively mobilized in efforts to colonize outer space and to develop vast digital networks of consumption and surveillance as it was mobilized by the environmental movement. Ecology's focus on energy as an animating feature of systems paralleled the increasing influence of systems thinking in understanding the ecology of the earth and in the development of digital technologies. It has helped us to make climate change legible, but has also underwritten the acceptance of illiberal concepts in popular environmentalism, such as "spaceship earth." ${ }^{21}$ It is worth thinking more deeply about these historical links to better understand the questions and opportunities that our current notions of energy open up and, perhaps more importantly, render untenable. Is our notion of energy separable from twentieth-century abundance or is it hindering how we think about pathways beyond our present impasse?

Although systems ecologists tended to favor holism and equilibrium over growth, the hegemonic political ideologies of the twentieth century pursued economic growth as the holy grail of peace and progress after a half century of global conflict. The analytical emphases of the energy humanities can help us to re-narrate this commitment too, opening up difficult questions about the viability of dominant approaches to economics, such as Keynesianism and neoliberalism. Since the late 1930s, the center-left has favored a Keynesian approach to economic policy. Its dominant narrative is that Keynesian stimulus spending paired with a welfare state generated the postwar "Golden Age of Capitalism" characterized by steady economic growth and relative social equality. This narrative concludes that capitalism can be regulated to reign in its worst excesses and generate sustained growth to benefit a significant majority, as only capitalism can. As Mitchell argues, however, the postwar economic boom depended on precipitous increases in oil consumption in the US and the industrialized West. One of Mitchell's signal contributions is to show that "the economy" as a distinct sphere of 
discourse and intervention is of relatively recent vintage, having emerged out of the interwar crisis to underwrite the continued viability of nation-states and the international system that they comprised. Crucially, the emergence and growth of "the economy" also depended on the increasing availability of oil. ${ }^{22}$ Flows of cheap oil allowed economies to grow (volume of exchange) without physical expansion (of land) and made the Bretton Woods system possible. This dependence eventually came into view in the 1970s, when the specter of energy scarcity wreaked economic havoc on now heavily oil-dependent nations.

Mitchell's insight about the relation between oil, the economy, and the Keynesian paradigm casts a shadow over the economic achievements of Keynesianism and of the twentieth century more broadly. If Keynesianism owed much of its success to the energy regime in which it was formulated, where does the center-left turn after oil? Would there have been a Golden Age of Capitalism without oil? Liberal capitalism's late-century triumph suddenly seems fragile. Moreover, given the historic reliance of communist states on industrial production and fossil-fueled imaginaries of abundance-histories that are still largely unwrittendoes the Left have any clear sense of how to achieve just living standards without oil?

The Marxist literary theorist Raymond Williams, writing in 1958, predicted that the central challenge of the twentieth century's second half would be the equitable distribution of wealth and resources to create a "good common culture." "The means to a good, abundant economy," he said, "we already understand." 23 Williams was writing in the early days of the Great Acceleration, when growing energy use was largely taken for granted. He recognized the role of "steam power, the petrol engine, [and] electricity" in relieving the backbreaking labor and poverty of rural life, and embraced them for that reason. ${ }^{24}$ When we bring energy into our analyses, however, we must confront whether or not we really do understand the "means to an abundant economy" that is fair and sustainable. This kind

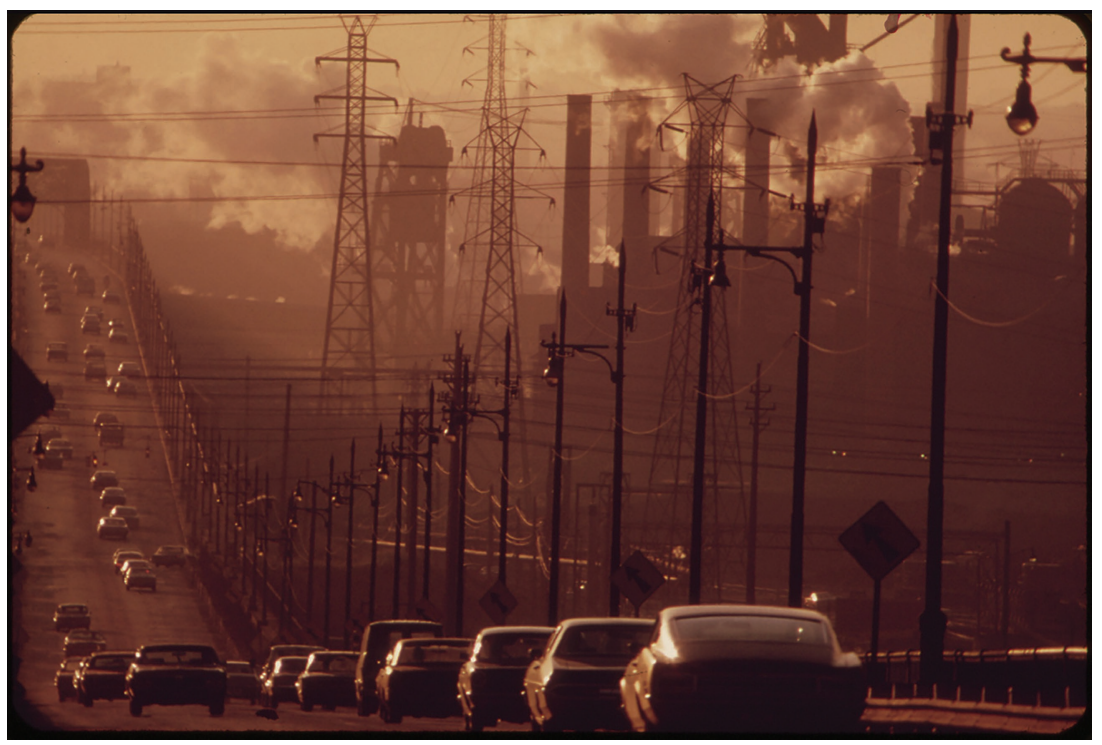

FIGURE 12.2 The environmental costs of the good life in the 1970s US. The original caption reads "Clark Avenue and Clark Avenue Bridge, looking east from West 13th Street, obscured by industrial smoke, in Cleveland, Ohio in July 1973." Source: EPA-DocumericaFrank Aleksandrowicz. Record Group 412, National Archives II, College Park, MD. 
of analysis and the insights it generates also pose tough questions, as Ghosh and others have pointed out, about other twentieth-century concepts, such as the standard of living and individual freedom, as we understand and live them today (Figure 12.2). ${ }^{25}$

Although Keynesianism remains influential and is periodically revived in contemporary political discourse, neoliberalism has surpassed it as the dominant socioeconomic paradigm. Neoliberalism's history, suppositions, and future transmogrify in light of energy. For instance, the ascendency of neoliberalism, which is typically dated by the elections of Margaret Thatcher and Ronald Reagan in 1979-1980, owes much to the 1970s energy crisis. Free market intellectuals and economists used that decade's energy woes to argue that overregulation, rather than excessive consumption, caused the problems of energy scarcity and expense, and that deregulating energy production and pricing would drive innovation to generate future energy abundance. Almost paradoxically, while neoliberals decried the "scarcity paradigm" of environmentalists who interpreted the energy crisis as a manifestation of the "limits to growth," the neoliberal economy of the 1980s sought economic growth and value generation in financialized abstraction, hence the proliferation of financial instruments and the growth of service industries. All of this relied, of course, on the offshoring of energy-intensive manufacturing, where the costs of labor could be reduced, and on an extensive network of container ships, transport trucks, and air freight to cover the world with endless flows of cheap commodities.

Attending to energy helps us to see neoliberalism as a response to the limits to growth and a denial of limits that deepened reliance on abstract energies. Its most recent iteration- the "New Economy" of "innovation" and digital technology- has only intensified these tendencies. It relies on techno-utopian visions of energy-efficient economies of creativity and information that rely not only on global networks of manufacturing, but also on the energyintensive infrastructures that undergird the internet, "the cloud," and the batteries needed to run it all. Like Keynesianism, neoliberalism continues to prioritize-even to obsess overeconomic growth. ${ }^{26}$ It also denies scarcity and assumes that the free market will drive the technological and economic innovations that we need to address our socio-technical problems, from climate change to housing and beyond. Neoliberalism presupposes energy abundance even as it fetishizes efficiency. Consequently, its values of radical individualism, choice, and growth must be understood in light of the energy conditions that surrounded their birth.

As fossil fuels tightened their grip on the world in the twentieth century, the cultural importance of their capacities and crises deepened. What might it mean, finally, to reimagine postmodernity - as a cultural and intellectual movement - in terms of energy, as a postenergy crisis phenomenon? The 1970s energy crisis threatened the material foundations of mid-twentieth-century life and caused many to question the viability of their petroculture and its spaces. When oil prices receded in the 1980s and the US reestablished geopolitical primacy in the Middle East, however, energy transition retreated to the margins. In its place roared an avalanche of discourse about the elimination of time and history and the primacy of space, and fascination with 24/7 televisual and digital connection, while globalization dominated the pages of the New York Times and the New Left Review. Is it possible to establish parallels between post-1973 financialization and postmodernity as denials of the limits to growth and escape into abstraction? How should a contemporary critical theory that faces the threat of climate change understand the intellectual legacy of the 1980s and 1990s? To what extent is the endless refashioning of the subject through digital interfaces an effect of fossil-fueled neoliberalism and its ideologies of entrepreneurial flexibility?

If the energy humanities is to help us to "return to the flow" or to realize some other future, it must also expand its purview to other forms of energy. This is very difficult in 
light of our contention that energy shapes us. How can we, as analysts peek above the fog? The critique of fossil fuels and of nuclear power will remain central, particularly since we are nowhere near transitioning away from them. But the generation of other possibilities and understanding of other limits will mean tracing the pasts of many forms of energy, including natural renewables (food and muscle), renewable technologies (solar, wind, geothermal), and others. We need to understand how these different forms have shaped and might still shape nature, social relations, and imaginaries. Present energy transition debates prioritize the maintenance of current forms of modernity, but without fossil fuels. The challenge that we face is to reimagine a modernity without nearly our present levels of fossil fuel use. Doing so will mean dismantling and repurposing the global petroleumscape that to date has preserved oil's power, as Dominic Boyer suggests. ${ }^{27}$ Perhaps the past can help in that respect as well.

\section{Theory After Energy}

The claim that forms of energy shape culture, society, and politics also has implications for (critical) theory. It demands the reinterpretation of the history of theory, particularly in the fossil-fueled twentieth century, and the reimagining of theory in light of this new understanding. Malm has recently made a similar point about climate change, namely that it is now a "shared litmus test" for contemporary theory, which must be able to make sense of the fossil economy that drives global warming. ${ }^{28}$ The energy humanities pose a similar but broader challenge to theory. Whereas Malm focuses on the immediacy of grasping climate change and the fossil economy, the energy humanities extends the challenge to all theory formulated over the past century and to all forms of energy. Although it shares Malm's sense of urgency about climate and fossil fuels, the energy humanities proposes that the material realities of all forms of energy carry social and political implications, as do the imaginaries that are often linked to those forms of energy.

In this section, we want to talk briefly about some of the implications of energy for how we understand theory, focusing on two broad areas: (1) politics and society, and (2) subjectivity. For the most part, the issues that energy raises for theory in these areas have yet to be worked out in detail; there are only a few works that link energy to theory explicitly. ${ }^{29}$ The role of energy in theory goes beyond politics and society and theories of subjectivity; there is an obvious need, for example, to develop the points of connection and disjuncture of the energy humanities from post-humanisms and new materialisms, including object-oriented ontologies. What follows is an initial map of the issues that might shape some aspects of theory after the introduction of energy into accounts of the cultural, social, and political—zones of experience marked deeply by energy, even if to date they have rarely been explored as such.

\section{Politics and Society}

Dipesh Chakrabarty has provocatively suggested that "The mansion of modern freedoms stands on an ever-expanding base of fossil fuel use. Most of our freedoms so far have been energy-intensive." 30 The development and extension of liberal freedoms (such as they are, and where they exist at all) since the Enlightenment is rarely narrated in relation to the expansion of the use of energy. Reading energy not only into the apparatus of freedom-in the liberal tradition, the operation of law to secure freedoms for and against-but also into our conceptual understanding of it would generate new insights into the character and 
materiality of political freedom. Re-narrating post-Enlightenment practices and verities in relation to energy would draw attention to the environmental implications of the political as such, and do so in a manner that pushes past the meek gestures that have constituted the majority of responses to global warming to date (e.g., carbon taxes-a continuation of the use of tax as a mechanism of liberty that dates back to Adam Smith). It might also tell us something about the threats to freedoms that lie just over the horizon, as access to abundant and cheap fossil fuels begins to wane, either as a result of the depletion of supplies or due to the environmental necessity of moving away from their use.

In addition to the lack of focus on the role of energy in liberal understandings of freedom, there has been virtually no attention to the role of energy in the operations of contemporary power, politics, and the spaces of governance, and whether these operations are figured in the language of standard political science or understood through the lens of the work of thinkers such as Michel Foucault. The careful elaboration of the rationale and mechanics of governmentality that Foucault outlines in his later lectures never describes the import of energy to the management of modern populations. It is not just that the operations of governmentality require energy and that access to more energy in turn animates new modes of governmentality, but that population is itself a phenomenon linked to energy. The expansion of modern populations that accompanied the increasing scale and intensity of energy use is deeply conjoined with rising levels of energy use; the capacity of states to intervene at the scale of the population to exercise governmentality also depends on access to ever-greater levels of energy. In his later lectures, Foucault also examined the development of neoliberalism as an aspect of modern governmentality. ${ }^{31}$ As we described earlier, one dimension of neoliberalism that is commonly stressed is the downloading of state responsibilities to the market. Here, too, there are practices in the flow of modern energy that can be seen as complicating this accepted narrative of neoliberalism. The externalization of the costs of ever-expanding car culture and suburban infrastructure to governments (a now global phenomenon) have helped markets stung by stalled or slow growth post-1973 to continue to support a belief in the growth of capitalist markets and of indefinitely increasing levels of energy.

Despite the obvious import of fossil fuel energy to the shape of contemporary politics and society, very few theorists have attempted to make certain that energy is part of the larger story of power. This is as true of Marxist theory as it is of other modes of political theory (the work of Bellamy and Diamanti is a notable exception). Marx's "Fragment on Machines" from the Grundrisse, which has played an important role in the reimagining of contemporary political theory on the Left, describes a world in which advanced technology frees labor from production. Even were technology able to set individuals free from work so that they might engage in self-development, these machines would still require energy to function. It is necessary to understand the energetic and environmental implications of the manner in which we frame political transformation. It is not only our understanding of capitalism that is impeded when we fail to factor energy into social theory, but also our imaginings of the character of social and political emancipation.

Some theorists have begun to refigure social and political theory with energy in mind via the use of new categories such as energy commons, energy ethics, or solar communism. ${ }^{32} \mathrm{~A}$ great deal of work remains to be done, insofar as these interventions continue to be mostly viewed as asides to the main narrative through which we theorize the politics and society of modernity. 


\section{Subjectivity}

If one had to summarize the past century and a half of theories of subjectivity-that is, when such theories overlap historically with the era of fossil fuels-what emerges as central is an insistence that subjects are not self-identical or self-present. In other words, the claim advanced in work from Marx to Freud and beyond is that there is no fixed, identifiable subject per se. To be a subject is to be something other than oneself, whether as a result of the dynamics of ideology and power or the operations of language, the psyche, and gender. While the phenomenological experience of being a subject is to understand oneself as oneself, the reality of being a subject is that one can never fully map the social, linguistic, and psychological forces that produce one's subjectivity - including the very sense that one is a subject qua subject.

What would it mean for our understanding of the subject if we were to recognize energy as a key element of subjectivity — as powerful a force of decentering the subject as language or ideology? As subjects have expanded their energy use over the course of modernity, they have extended their capacities (from slowly walking to flying over oceans in a matter of hours), created new spatial relations, and have molded their sense of selfhood in relation to the abilities that energy affords. Energy might thus be viewed as something like the discourse networks explored in the work of Friedrich Kittler-akin to the mechanisms of communication (pens, typewriters, film, etc.) that are key to the production of subjectivity. ${ }^{33}$ Yet, fossil fuel energy goes beyond communication systems in its import to subjectivity. In "The Resources of Fiction," literature scholar Graeme Macdonald writes: "Oil's emancipatory role in habitual experience is repeatedly vaunted in this incorporating system of petro-acculturation: how could we live without it?"34 The deep, unspoken, and largely untheorized connection between the subject and energy - one of the core relations in the construction of the petroleumscapecan be witnessed in the difficulty of imagining how one could be a subject at all in the absence of energy. Allan Stoekl notes that "In speaking of the finitude of energy supplies, we are only speaking of the limits to the human, the fundamentally limited availability of ordered energy capable of doing 'work' for Man. We are speaking, in other words, of death, of the incommensurability of intimate Nature." 35 Subjectivity has become fossil fueled; this is likely one of the key reasons why it is so difficult to imagine (much less actually undertake) a transition away from oil and the spaces that oil has birthed around the world.

Theorists interested in adding energy to subjectivity have frequently gestured to Patricia Yaeger's identification of an "energy unconscious." Her identification of this unconscious is provocative, even if in her work she is speaking not of a mode of subjectivity but of a method of reading for energy (an extension of Fredric Jameson's The Political Unconscious [1981]). ${ }^{36}$ Nevertheless, the intent of this notion of an "energy unconscious" is to position energy at the core of subjectivity in a way that must be accounted for, both with respect to the subject of oil and to whatever subject might be brought into being via energy transition. Herbert Marcuse captures the notion of energy unconscious in his description of the subjective depths required for genuine social change:

Our world emerges not only in the pure form of time and space, but also, and simultaneously, as a totality of sensuous qualities-object not only of the eye (synopsis) but of all human senses (hearing, smelling, touching, tasting). It is this qualitative, elementary, unconscious, or rather preconscious, constitution of the world of experience, it is this primary experience itself which must change radically if social change is to be radical, qualitative change. ${ }^{37}$ 


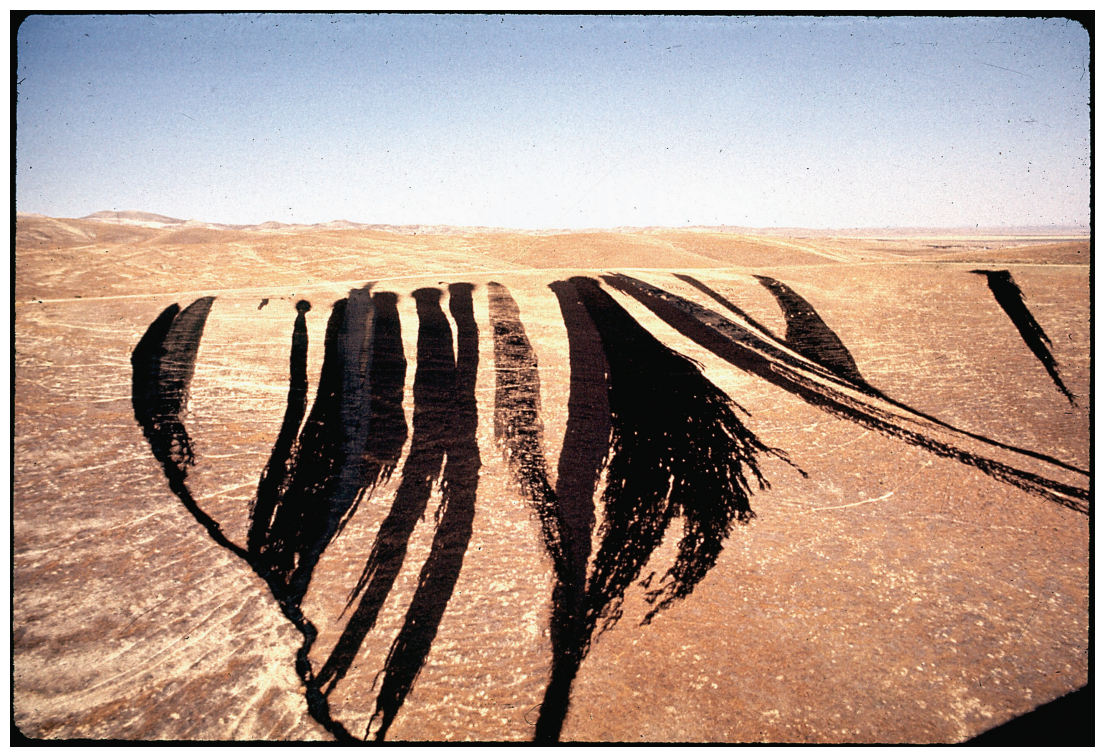

FIGURE 12.3 "Oil waste on a barren hillside." Source: EPA-Documerica—Gene Daniels. Record Group 412, National Archives II, College Park, MD.

Jordan Kinder's remapping of Louis Althusser's notion of ideology and ideological state apparatuses by adding energy performs a similar function: to insist that the modern subject is an energy subject and the operations of subjectivity cannot be understood without considering energy (Figure 12.3). ${ }^{38}$

As with our discussion of political and social theory above, it is important to insist here too that the aim of theorizing subjectivity in relation to energy is not to create a subfield of academic analysis of petro-subjectivity. It is, rather, to insist that all theories of the subject have to be alert to the impact and import of energy. The Lacanian subject, for instance, should always already be imagined as a Lacanian petro-subject; this addition of energy to our understanding of the subject might in turn cause us to reimagine (in this instance) the operations of the psyche.

\section{Conclusion: The Politics of Energy in the Twenty-First Century}

The political struggles and debates over the petroleumscape in Canada are taking place in many parts of the world. Do we continue to build more pipelines and other fossil fuel infrastructures and the spaces associated with them to support a growing planetary population, or is this the moment to put on the brakes? How do we minimize fossil fuel use even while extending to much of the planet's population access to more energy (and with it, some of the undeniable benefits of petromodernity)?

Answering these questions requires that we begin to ask-and answer-the questions that the energy humanities prompt about the complex ways in which we have shaped ourselves into creatures of petromodernity inhabiting a global petroleumscape. Anything approximating energy transition requires that we commit ourselves to refiguring the codes, practices, and infrastructures of oil modernity - a challenge that goes far beyond any insistence that, from now on, we just leave the stuff in the ground. The struggle to bring about a fossil fuel transition demands that we more fully understand the shape, form, character, and 
history of the petroleumscape we inhabit today - a planetary space of oil that we continue to mistake for the norms and patterns of everyday life. As the various contributions to this book have shown, we can no longer afford to make this mistake.

\section{Notes}

1 See Government of Canada, "Crude Oil Facts," https://www.nrcan.gc.ca/energy/facts/crudeoil/20064, accessed January 7, 2021.

2 J. R. McNeill and Peter Engelke, The Great Acceleration: An Environmental History of the Anthropocene Since 1945 (Cambridge, MA: Harvard University Press, 2016); Amitav Ghosh, The Great Derangement: Climate Change and the Unthinkable (Chicago, IL: University of Chicago Press, 2016).

3 Jeff Diamanti and Mark Simpson, "Five Theses on Sabotage in the Shadow of Fossil Capital," Radical Philosophy 2, no. 2 (2018): 3-13, 3.

4 Jean-Claude Debeir, Jean-Paul Deléage, and Daniel Hémery, In the Servitude of Power: Energy and Civilization through the Ages, trans. John Barzman (New York: Zed Books, 1991), 13.

5 Ibid, 237.

6 Timothy Mitchell, Carbon Democracy: Political Power in the Age of Oil (New York: Verso, 2011), 9.

7 Andreas Malm, Fossil Capital: The Rise of Steam Power and the Roots of Global Warming (New York: Verso, 2016).

8 Ghosh, The Great Derangement; Dipesh Chakrabarty, "The Climate of History: Four Theses," Critical Inquiry 35, no. 2 (2009): 197-222.

9 See, e.g., Imre Szeman and Dominic Boyer, "Introduction: On the Energy Humanities," in Energy Humanities: An Anthology, eds. Imre Szeman and Dominic Boyer (Baltimore, MD: Johns Hopkins University Press, 2017), 1-13; Jennifer Wenzel, "Introduction," in Fueling Culture: 101 Words on Energy and Environment, eds. Imre Szeman, Jennifer Wenzel, and Patricia Yaeger (New York: Fordham University Press, 2017), 1-16.

10 J. R. McNeill, Something New Under the Sun: An Environmental History of the Twentieth-Century World (New York: W.W. Norton \& Company, 2000); Vaclav Smil, Energy and Civilization: A History (Cambridge, MA: MIT Press, 2017); E. A. Wrigley, Energy and the English Industrial Revolution (Cambridge: Cambridge University Press, 2010).

11 Reinhart Koselleck, Futures Past: On the Semantics of Historical Time, trans. Keith Tribe (New York: Columbia University Press, 2004), 11.

12 See Janet Roitman, Anti-Crisis (Durham, NC: Duke University Press, 2013), 9ff.

13 Walter Benjamin, "On Some Motifs in Baudelaire," in Illuminations, ed. Hannah Arendt, trans. Harry Zohn (London: Jonathan Cape, 1970), 157-202.

14 See Christopher Wells, Car Country: An Environmental History (Seattle: University of Washington Press, 2012); Carola Hein, "Oil Spaces: The Global Petroleumscape in the Rotterdam/The Hague Area," Journal of Urban History 44, no. 5 (September 2018): 887-929.

15 E. P. Thompson, The Making of the English Working Class (New York: Vintage, 1966); Anson Rabinbach, The Human Motor: Energy, Fatigue, and the Origins of Modernity (Berkeley: University of California Press, 1992).

16 Malm, Fossil Capital.

17 Jonathan Crary, 24/7: Late Capitalism and the Ends of Sleep (New York: Verso, 2014); Dominic Pettman, Infinite Distraction (Cambridge: Polity, 2016).

18 See Stephen Kern, The Culture of Time and Space, 1880-1918, 2nd ed. (Cambridge, MA: Harvard University Press, 2003).

19 Rabinbach, Human Motor.

20 Joel B. Hagen, An Entangled Bank: The Origins of Ecosystem Ecology (New Brunswick, NJ: Rutgers University Press, 1992).

21 Peder Anker, From Bauhaus to Ecohouse: A History of Ecological Design (Baton Rouge: Louisiana State University Press, 2011).

22 Timothy Mitchell, "Carbon Democracy," Economy and Society 38, no. 3 (August 2009): 399-432 and "Fixing the Economy," Cultural Studies 12, no. 1 (1998): 82-101.

23 Raymond Williams, "Culture is Ordinary," in Cultural Theory: An Anthology, eds. Imre Szeman and Timothy Kaposy (Oxford: Wiley-Blackwell, 2010), 56-57.

24 Ibid. 
25 Bob Johnson, Carbon Nation: Fossil Fuels in the Making of American Culture (Lawrence: University Press of Kansas, 2014).

26 Philip Mirowski, Never Let a Serious Crisis Go to Waste: How Neoliberalism Survived the Financial Meltdown (London: Verso, 2013).

27 Dominic Boyer, "Revolutionary Infrastructure," in Infrastructures and Social Complexity: A Companion, eds. Penelope Harvey, Casper Jensen, and Atsuro Morita (New York: Routledge, 2017): 174-86.

28 Malm, Fossil Capital, 16.

29 Brent Bellamy and Jeff Diamanti. Materialism and the Critique of Energy (Toronto: MCM Prime, 2018).

30 Chakrabarty, "Climate of History," 208.

31 Michel Foucault, The Birth of Biopolitics: Lectures at the College de France, 1978-79, ed. Michel Senellart, trans. Graham Burchell (New York: Palgrave Macmillan, 2008).

32 George Caffentzis, "The Petroleum Commons," Counterpunch (December 15, 2004), www. counterpunch.org/2004/12/15/the-petroleum-commons/, accessed September 12, 2018; Giovanni Frigo, "Energy Ethics, Homogenization, and Hegemony: A Reflection on the Traditional Energy Paradigm," Energy Research and Social Science 30 (2017): 7-17; Patricia S. Mann, "On the Precipice with Naomi Klein, Karl Marx and the Pope: Towards a Postcapitalist Energy Commons and Beyond," Radical Philosophy Review (August 2016), https://www.pdcnet.org/radphilrev/ content/radphilrev_2016_0999_8_8_64; David Schwartzman, "Solar Communism," Science E Society 60, no. 3 (1996): 307-31; Jessica Smith and Mette High, "Exploring the Anthropology of Energy: Ethnography, Energy and Ethics," Energy Research and Social Science 30 (2017): 1-6.

33 Friedrich Kittler, Gramophone, Film, Typewriter, trans. Geoffrey Winthrop-Young and Michael Wutz (Stanford, CA: Stanford University Press, 1999).

34 Graeme Macdonald, "The Resources of Fiction," Reviews in Cultural Theory 4, no. 2 (2013): 11. Emphasis in original.

35 Allan Stoekl, Bataille's Peak: Energy, Religion and Postsustainability (Minneapolis: University of Minnesota Press, 2007), 200.

36 Patricia Yaeger, "Editor's Column: Literature in the Ages of Wood, Tallow, Coal, Whale, Oil, Gasoline, Atomic Power, and Other Energy Sources,” PMLA 126, no. 2 (2011): 305-26, 3; Fredric Jameson's The Political Unconscious (1981).

37 Herbert Marcuse, "Nature and Revolution," in Counter-Revolution and Revolt (Boston, MA: Beacon Press, 1972), 63. Emphasis in original.

38 Jordan Kinder, "The Coming Transition: Fossil Capital and Our Energy Future," Socialism and Democracy 30, no. 2 (2016): 8-27. 